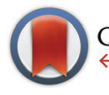

CrossMark $\leftarrow$ click for updates

Cite this: Dalton Trans., 2016, 45 6329

Received 14th February 2016,

Accepted 3rd March 2016

DOI: 10.1039/c6dt00611f

www.rsc.org/dalton

\section{A facile, green and efficient surfactant-free method for synthesis of aluminum nanooxides with an extraordinary high surface area $\dagger$}

\author{
Gholamhossein Mohammadnezhad, ${ }^{* a}$ Oluseun Akintola, ${ }^{\mathrm{b}}$ Winfried Plass, ${ }^{\mathrm{b}}$ \\ Frank Steiniger ${ }^{\mathrm{c}}$ and Martin Westermann ${ }^{\mathrm{c}}$
}

\begin{abstract}
Nano boehmite with unprecedented high surface area and pore volume $\left(802 \mathrm{~m}^{2} \mathrm{~g}^{-1}, 2.35 \mathrm{~cm}^{3} \mathrm{~g}^{-1}\right)$ was prepared using a facile, green and efficient surfactant-free synthesis method. The structure of the material is characterized by the presence of plates with varying thicknesses and morphologies. The calcined samples show curved and rolled plates with a nanotube-like appearance.
\end{abstract}

Nanoscience and nanotechnology, in which the objects or features studied are typically in the range of 1-100 $\mathrm{nm}$, have been among the most important developing areas in the last few years. Synthesis, characterization, and application of nanoparticles are of fundamental importance to this field. In this regard, a large number of methods such as co-precipitation, sol-gel processes including hydrolytic and non-hydrolytic, hydrothermal, solvothermal, microwave-assisted, and sonochemical methods, template utilization, and biomimetic methods, or a combination of two or more of the above mentioned methods, have been developed for the controlled synthesis of the desired nanoparticles. ${ }^{1,2}$

Utilization of surfactants in nanomaterial synthesis is of particular importance due to their tendency to affect the chemical, physical, and structural properties of the latter, such as size, shape, porosity, and dispersibility. ${ }^{3-6}$ However, usage of surfactants is not without its own drawbacks, such as their uncertain biocompatibility in addition to their irreversible adsorption on the surface of nanoparticles. Often the latter case leads to an unpredictable and undesirable impact on their properties, resulting in the reduction of the accessible

\footnotetext{
${ }^{a}$ Department of Chemistry, Isfahan University of Technology, Isfahan 84156-83111, Iran.E-mail:mohammadnezhad@cc.iut.ac.ir

${ }^{b}$ Institute of Inorganic and Analytical Chemistry, Chair of Inorganic Chemistry II, Friedrich Schiller University Jena, Humboldtstr. 8, 07743 Jena, Germany.

E-mail: sekrplass@uni-jena.de

${ }^{c}$ Electron Microscopy Center, Jena University Hospital, Ziegelmühlenweg 1, 07743 Jena, Germany

$\dagger$ Electronic supplementary information (ESI) available. See DOI: 10.1039/ c6dt00611f
}

surface which is a crucial point to be considered especially when catalytic applications are the goal. ${ }^{5-8}$

The commonly used media for surfactant-free synthesis of inorganic nanoparticles over time have been aqueous or nonaqueous and these could be under hydrolytic or nonhydrolytic conditions. Some important features of the surfactant-free methods such as higher yields, lower impurities, utilization of green solvents, simplicity, and greater accessible surface area make them both scientifically and economically interesting. ${ }^{79-13}$ However, the aqueous approach led to certain limitations being observed, such as low or lack of crystallinity, need for strict control of synthetic conditions, and complicated hydrolytic behavior arising from the dual character of water as a solvent and ligand. ${ }^{14-16}$ An obvious alternative to the aqueous approach is to exclude water and this has drawn a considerable amount of interest. In this method, organic species play a large role in the synthesis of the nanoparticles but detailed information regarding the mechanism is not yet clearly understood. ${ }^{17-19}$

Among the wide variety of different nanomaterials, which have been prepared from different routes as mentioned above, nanocrystalline aluminum oxides occupy a particularly interesting niche. They have been used in many industrial processes as adsorbents, in catalysis, as catalyst components, in optics, electronics, high performance ceramics, and in many other applications. ${ }^{20-24}$ Syntheses of these materials with enhanced properties, in particular, their surface area, pore volume, morphology, and dimensionality continue to receive extraordinary attention. ${ }^{25-33}$

Alumina $\left(\mathrm{Al}_{2} \mathrm{O}_{3}\right)$ and boehmite (AlOOH) have already been prepared by a wide variety of methods, among which is the Bayer process, a famous industrial method for the large scale production of aluminum oxides. ${ }^{34-39}$ However, this method still has a few shortcomings such as the large amount of impurities accompanying the products which hampers the utilization of these aluminum oxides as the substrate material for LEDs (light emitting diodes) and other applications ${ }^{40}$ An alternative method is the utilization of aluminum alkoxides as pure molecular precursors. ${ }^{3}$ In 1986 Fanelli reported the reaction of aluminum sec-butoxide in 2-butanol, the parent 
alcohol, with in situ generated water from alcohol dehydration at $250{ }^{\circ} \mathrm{C}$ in an autoclave reactor and obtained high surface area amorphous aluminum oxide. ${ }^{41} \mathrm{~A}$ similar reaction in the presence of acid led to the formation of boehmite along with aluminum sulfate with lower surface area $\left(50 \mathrm{~m}^{2} \mathrm{~g}^{-1}\right)$. Jun et al. not too long ago presented a method for the preparation of high surface area boehmite and alumina via hydrolysis of aluminum alkoxides in their parent alcohols. ${ }^{42}$

Herein, we describe a method for the preparation of high surface area nano boehmite and alumina by using a surfactant-free modified sol-gel route which has been performed in a shorter time with higher surface area and different morphologies to the ones previously reported. A particular feature of this method is avoiding the use of any surfactants as a template and the utilization of pure aluminum alkoxides in their parent alcohol and subsequent hydrolysis of the precursors in the presence of a small portion of aqueous solution of an organic acid with short drying times. The versatility of this method should allow for the synthesis of a wide variety of other single or mixed metal oxide nanomaterials as well as the synthesis of highly pure in situ prepared doped semiconductors. Furthermore, modifications of the surface of these nanoparticles make them valuable candidates for targeting applications.

Nano boehmite and $\gamma$-alumina were prepared using an accessible and reliable surfactant-free method which does not need any expensive template and stabilizer. It also involves the hydrolysis of clear solutions of either aluminum 2-propoxide or aluminum 2-methoxyethoxide, as single source molecular precursors, in 2-propanol and 2-methoxyethanol (their parent alcohol), respectively. Hydrolysis was performed by addition of a small portion of aqueous solution of acetic acid followed by reflux and aging for $24 \mathrm{~h}$. One of the key factors in this step is the reflux temperature which is determined by the type of the utilized alcohol. Boiling temperatures of 2-propanol and 2-methoxyethanol are about 83 and $125{ }^{\circ} \mathrm{C}$, with the latter being in the suitable range for preparation of nano boehmite. The side-product of the reaction in this stage is liberated alcohol which is also the solvent in addition to a small amount of water and an organic acid. In contrast to the aqueous method, the alcohol was simply recovered by taking advantage of the lower surface tension of the mixture through distillation at lower temperatures using a rotary evaporator thus reducing energy consumption while simultaneously avoiding time consuming filtration. The samples were then dried at 120 mbar, and mild temperature $\left(70^{\circ} \mathrm{C}\right)$ in a short time $(3 \mathrm{~h})$ to remove acetic acid. The obtained powders from aluminum 2-propoxide and aluminum 2-methoxyethoxide molecular precursors are named Al-1 and Al-2, respectively and were characterized by wide angle X-ray diffraction (WA-XRD), $\mathrm{N}_{2}$ adsorption-desorption, and TEM measurements.

Fig. 1 shows the WA-XRD data of the dried samples at $70{ }^{\circ} \mathrm{C}$. The data reveals formation of the boehmite phase in both cases (JCPDS card no. 00-005-0190). Since the reflux temperatures of the samples were at the boiling point of their parent alcohols, $\mathrm{Al}-2$ was reacted at a higher temperature and consequently showed better crystallinity. Subsequently, both

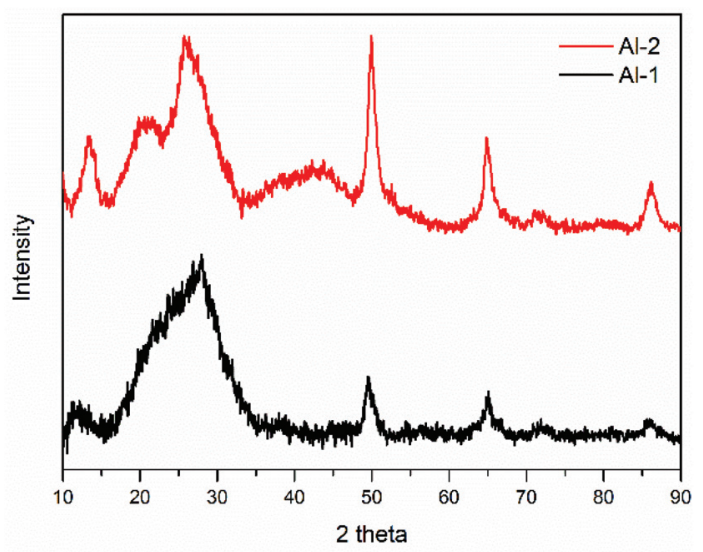

Fig. 1 Wide-angle XRD patterns for samples Al-1 and Al-2 dried at $70^{\circ} \mathrm{C}$.

samples were calcined at 600 and $800{ }^{\circ} \mathrm{C}$. The wide-angle XRD patterns for the samples $\mathrm{Al}-1$ and $\mathrm{Al}-2$ are depicted in Fig. S1 and $\mathrm{S} 2, \dagger$ respectively. In both cases, calcination at $800{ }^{\circ} \mathrm{C}$ results in conversion of boehmite to $\gamma$-alumina as the crystalline phase (JCPDS card no. 10-0425). For Al-1 the formation of $\gamma$-alumina is already observed at $600^{\circ} \mathrm{C}$, whereas for $\mathrm{Al}-2$ no significant reflections were detected for the sample calcined at $600^{\circ} \mathrm{C}$.

Fig. 2 depicts the $\mathrm{N}_{2}$ adsorption-desorption isotherms and pore size distributions of the as-prepared and calcined samples at 600 and $800{ }^{\circ} \mathrm{C}$. According to the IUPAC classification, these isotherms exhibit classical type IV isotherms. ${ }^{43}$ The clearly observed type IV isotherms along with hysteresis loops are typical for mesoporous materials. Moreover, it is evident that the hysteresis loops of Al-1 and Al-2 are not similar. For Al-2 hysteresis loops of type $\mathrm{H} 2$ are observed while $\mathrm{Al}-1$ exhibits no limiting uptake in the range of high $P / P^{0}$ and reveals hysteresis loops of type H3. It has already been established that there exists a correlation between the shape of the hysteresis loop and the texture properties of mesoporous materials such as pore size, pore size distribution, and their connections. The data of Al-1 indicates the presence of non-rigid aggregates of the platelike framework giving rise to slit-shaped mesopores. For Al-2 on the other hand, the appearance of its isotherm already suggests the presence of both micropores and mesopores within its pore structure. This was confirmed via applying the De-Boer thickness method to obtain the micropore areas (see Fig. S3 and Table $\mathrm{S} 1 \dagger)$. The shape of its hysteresis loop is indicative of the presence of pore blocking effects as seen from the sudden step-down upon closing up, a major characteristic of the H2. Despite the utilization of the same procedure in preparation of the samples, different structural data were obtained, which demonstrates the importance of the selected precursors on their characteristics.

Table 1 summarizes the physicochemical properties of Al-1 and $\mathrm{Al}-2$ including BET surface areas, pore volumes and mean pore diameters.

Remarkably, Al-1, the nano boehmite prepared from the aluminum 2-propoxide precursor shows an extraordinary high specific surface area of $802 \mathrm{~m}^{2} \mathrm{~g}^{-1}$ paired with a high pore 

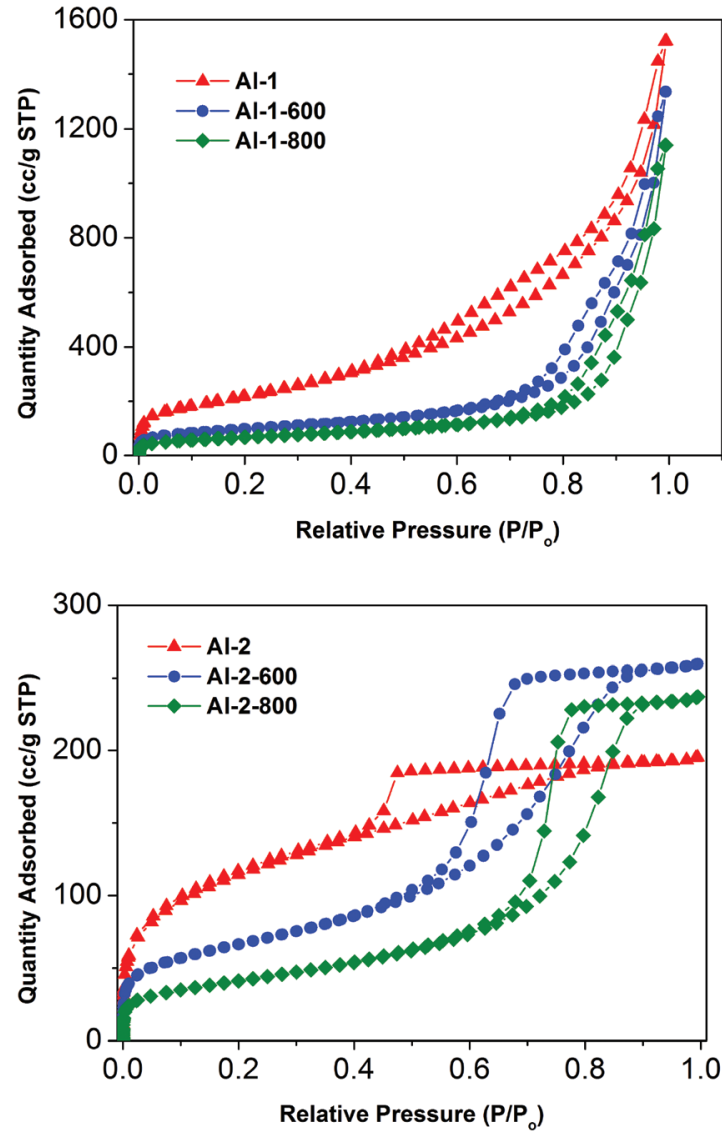

Fig. 2 Nitrogen adsorption-desorption isotherms of Al-1 (top) and Al-2 (bottom) dried at $70{ }^{\circ} \mathrm{C}$, and calcined at $600{ }^{\circ} \mathrm{C}$ and $800{ }^{\circ} \mathrm{C}$ represented with red, blue, and green symbols, respectively.

Table 1 Pore structure parameters of the samples obtained from alkoxide precursors

\begin{tabular}{|c|c|c|c|c|}
\hline Compound & $\begin{array}{l}\text { Calcination } \\
\text { temperature } \\
\left({ }^{\circ} \mathrm{C}\right)\end{array}$ & $\begin{array}{l}\text { BET surface } \\
\text { area }\left(\mathrm{m}^{2} \mathrm{~g}^{-1}\right)\end{array}$ & $\begin{array}{l}\text { Total pore } \\
\text { volume } \\
\left(\mathrm{cm}^{3} \mathrm{~g}^{-1}\right)\end{array}$ & $\begin{array}{l}\text { Average pore } \\
\text { width (nm) }\end{array}$ \\
\hline \multirow[t]{3}{*}{ Al-1 } & - & 802 & 2.35 & 11.7 \\
\hline & 600 & 343 & 2.07 & 24.1 \\
\hline & 800 & 242 & 1.77 & 29.2 \\
\hline \multirow[t]{3}{*}{ Al-2 } & - & 420 & 0.30 & 2.9 \\
\hline & 600 & 239 & 0.40 & 6.7 \\
\hline & 800 & 149 & 0.37 & 9.9 \\
\hline
\end{tabular}

volume of $2.35 \mathrm{~cm}^{3} \mathrm{~g}^{-1}$. This is in contrast to the common observation in the case of aluminas derived from aqueous based synthesis, which show an inverse relationship between the total pore volume and the surface areas. In fact, for Al-1 the pore volume shows a direct relationship to the surface area, with both parameters decreasing at higher calcination temperatures. Similar trends are observed for Al-2, however, with the exception of a comparatively low total pore volume for the as-prepared sample. Interestingly, the average pore size distribution of both samples shows related trends (see Fig. S4 and Table S2 $\dagger$ ).
The TEM images of samples Al-1 and $\mathrm{Al}-2$ obtained after vacuum drying and calcination $\left(600\right.$ and $\left.800{ }^{\circ} \mathrm{C}\right)$ are depicted in Fig. 3 and 4, respectively. The samples dried at $70^{\circ} \mathrm{C}$ show the presence of plates with varying thicknesses which are

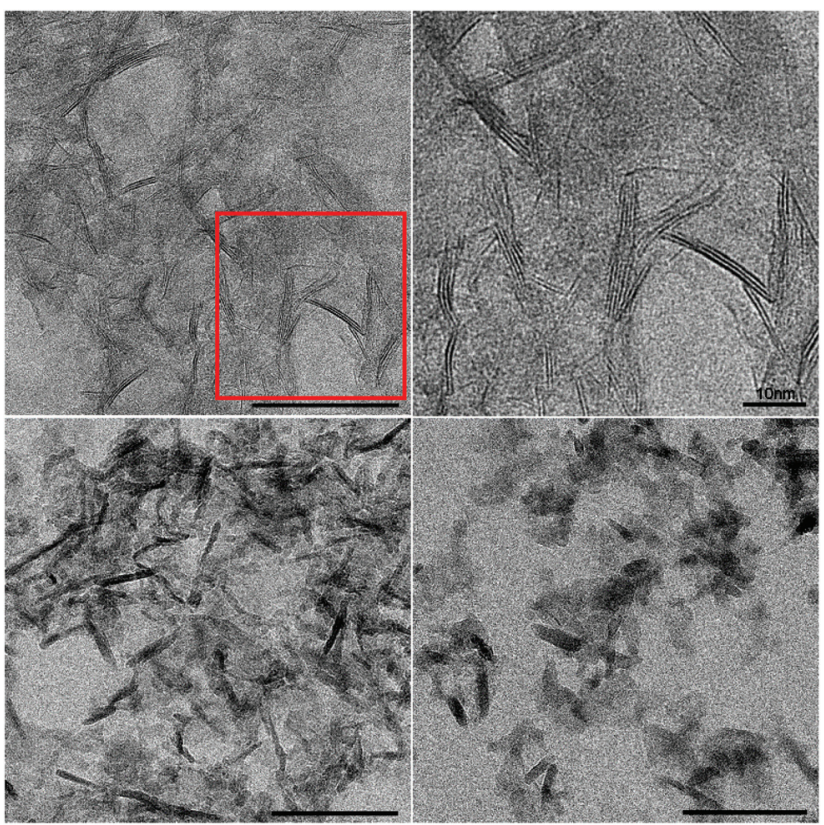

Fig. 3 (Top, left) TEM image of Al-1 dried at $70{ }^{\circ} \mathrm{C}$ and expanded part from the area in the red rectangle (top, right); (bottom, left) TEM image of Al-1 calcined at $600^{\circ} \mathrm{C}$; (bottom, right) TEM image of Al-1 calcined at $800^{\circ} \mathrm{C}$. Not labeled scale bars: $50 \mathrm{~nm}$.

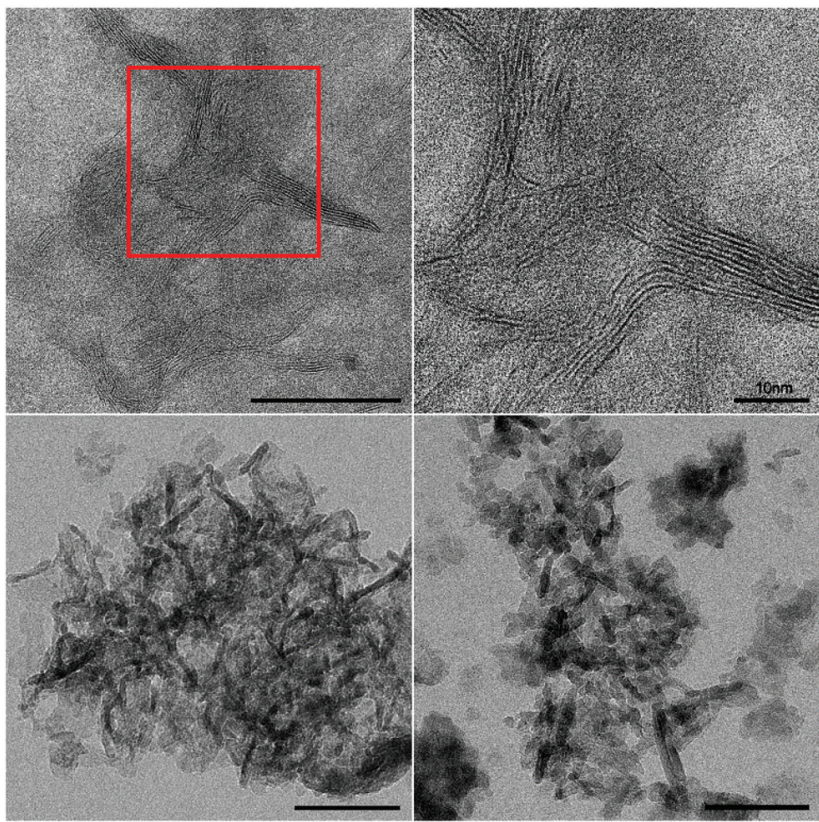

Fig. 4 (Top, left) TEM image of $\mathrm{Al}-2$ dried at $70{ }^{\circ} \mathrm{C}$ and the expanded part from the area in the red rectangle (top, right); (bottom, left) TEM image of $\mathrm{Al}-2$ calcined at $600^{\circ} \mathrm{C}$; (bottom, right) TEM image of Al-2 calcined at $800^{\circ} \mathrm{C}$. Not labeled scale bars: $50 \mathrm{~nm}$. 
folded and show aggregation (Fig. 3 and 4, top). High temperature treatment at 600 and $800{ }^{\circ} \mathrm{C}$ not only leads to formation of $\gamma$-alumina but also results in a change of morphology leading to more curved and partially rolled plates with a nanotube-like appearance (Fig. 3 and 4, bottom).

A remarkable advantage of the presented method is the avoidance of any non-green, environmental polluting organic solvents in addition to the ease of recovery of the employed alcohol. The use of small amounts of water and an organic acid facilitates elimination of the alcohol and distillation processes at lower temperatures leading to conservation of the structure and enabling the preparation of high purity materials.

To conclude, the presented procedure represents a surfactant-free method for the synthesis of boehmite (AlOOH) and $\gamma$-alumina $\left(\mathrm{Al}_{2} \mathrm{O}_{3}\right)$ with substantially high surface area and pore volume from easily prepared non-commercial aluminum alkoxides. The ability to recover and reuse the solvent in a short time is economically favorable, and hydrolysis using a small portion of aqueous organic acid facilitates both the distillation and drying processes.

\section{Acknowledgements}

We gratefully acknowledge the Iran National Science Foundation (INSF) for supporting this study. Partial support from the Research Affairs Division of Isfahan University of Technology (IUT) is also acknowledged. The financial support of the Deutsche Forschungsgemeinschaft (DFG: PL 155/14) is gratefully acknowledged. O. A. thanks the "Evangelisches Studienwerk Villigst e.V." for a scholarship. We thank Mrs Wermann for measuring the powder diffraction data.

\section{Notes and references}

1 C. N. R. Rao, H. R. Matte, R. Voggu and A. Govindaraj, Dalton Trans., 2012, 41, 5089-5120.

2 B. L. Cushing, V. L. Kolesnichenko and C. J. O'Connor, Chem. Rev., 2004, 104, 3893-3946.

3 G. Mohammadnezhad, O. Akintola, W. Plass, F. Schacher, F. Steiniger and M. Westermann, RSC Adv., 2015, 5, 4949349499 and references therein.

4 Y. W. Jun, J. S. Choi and J. Cheon, Angew. Chem., Int. Ed., 2006, 45, 3414.

5 J. Park, J. Joo, S. G. Kwon, Y. Jang and T. Hyeon, Angew. Chem., Int. Ed., 2007, 46, 4630.

6 G. R. Patzke, Y. Zhou, R. Kontic and F. Conrad, Angew. Chem., Int. Ed., 2011, 50, 826.

7 N. Pinna and M. Niederberger, Angew. Chem., Int. Ed., 2008, 47, 5292 .

8 S. K. Sahoo, J. Panyam, S. Prabha and V. Labhasetwar, J. Controlled Release, 2002, 82, 105.

9 G. Garnweitner and M. Niederberger, J. Am. Ceram. Soc., 2006, 89, 1801.
10 E. Sattarzadeh, G. Mohammadnezhad and M. M. Amini, Mater. Lett., 2011, 65, 527.

11 G. Mohammadnezhad, M. M. Amini and H. R. Khavasi, Dalton Trans., 2010, 39, 10830.

12 G. Mohammadnezhad and M. M. Amini, J. Sol-Gel Sci. Technol., 2016, 77, 378.

13 Z. Li, J. Han, L. Fan and R. Guo, CrystEngComm, 2015, 17, 1952.

14 A. Dessombz, D. Chiche, P. Davidson, P. Panine, C. Chanéac and J. P. Jolivet, J. Am. Chem. Soc., 2007, 129, 5904.

15 J. P. Jolivet, C. Froidefond, A. Pottier, C. Chanéac, S. Cassaignon, E. Tronc and P. Euzen, J. Mater. Chem., 2004, 14, 3281.

16 X. Xia, Y. Zhang, D. Chao, C. Guan, Y. Zhang, L. Li and H. J. Fan, Nanoscale, 2014, 6, 5008.

17 Y. Yin and A. P. Alivisatos, Nature, 2005, 437, 664.

18 S. H. Yu, A. Pucci, T. Herntrich, M. G. Willinger, S. H. Baek, Y. E. Sung and N. Pinna, J. Mater. Chem., 2011, 21, 806.

19 M. Stefik, F. J. Heiligtag, M. Niederberger and M. Grätzel, ACS Nano, 2013, 7, 8981.

20 M. Trueba and S. P. Trasatti, Eur. J. Inorg. Chem., 2005, 17, 3393.

21 S. Gunduz and T. Dogu, Appl. Catal., B, 2015, 168, 497.

22 Y. Inoue, T. Matsumura, M. Hazumi, A. T. Lee, T. Okamura, A. Suzuki and H. Yamaguchi, Appl. Opt., 2014, 53, 1727.

23 G. Zhang, H. Wu, C. Chen, T. Wang, W. Wu, J. Yue and C. Liu, ACS Appl. Mater. Interfaces, 2015, 7, 5522.

24 T. Zhang, Y. Zhou, M. He, X. Bu, Y. Wang and C. Zhang, J. Eur. Ceram. Soc., 2015, 35, 1337.

25 S. Faramawy, M. S. El-Shall, M. A. El Wahed, T. Zaki and H. A. El Salam, J. Am. Sci., 2014, 10, 139.

26 B. Huang, C. H. Bartholomew and B. F. Woodfield, Microporous Mesoporous Mater., 2014, 183, 37.

27 D. N. Kelly, R. H. Wakabayashi and A. M. Stacy, ACS Appl. Mater. Interfaces, 2014, 6, 20122.

28 Q. Wu, F. Zhang, J. Yang, Q. Li, B. Tu and D. Zhao, Microporous Mesoporous Mater., 2011, 143, 406.

29 S. M. Grant and M. Jaroniec, J. Mater. Chem., 2012, 22, 86.

30 W. Q. Jiao, M. B. Yue, Y. M. Wang and M. Y. He, Microporous Mesoporous Mater., 2012, 147, 167.

31 S. Shen, W. K. Ng, L. S. O. Chia, Y. Dong and R. B. H. Tan, Cryst. Growth Des., 2012, 12, 4987.

32 W. Cai, J. Yu, C. Anand, A. Vinu and M. Jaroniec, Chem. Mater., 2011, 23, 1147.

33 P. F. Fulvio, R. I. Brosey and M. Jaroniec, ACS Appl. Mater. Interfaces, 2010, 2, 588.

34 G. Zhao, L. Xia, B. Zhong, L. Song and G. Wen, Ceram. Int., 2015, 41, 2590.

35 H. A. Dabbagh and M. Shahraki, Microporous Mesoporous Mater., 2013, 175, 8.

36 P. Pardo, N. Montoya and J. Alarcón, CrystEngComm, 2015, 17, 2091.

37 N. M. Vitorino, A. V. Kovalevsky, J. C. Abrantes and J. R. Frade, J. Eur. Ceram. Soc., 2015, 35, 3119.

38 B. Tang, J. Ge, L. Zhuo, G. Wang, J. Niu, Z. Shi and Y. Dong, Eur. J. Inorg. Chem., 2005, 21, 4366. 
39 A. R. Hind, S. K. Bhargava and S. C. Grocott, Colloids Surf., A, 1999, 146, 359.

40 H. Ozaki and T. Fukuda, U.S. Patent Application, 14/404114, 2013.

41 A. J. Fanelli and J. V. Burlew, J. Am. Ceram. Soc., 1986, 69, C-174.
42 K. W. Jun, Y. J. Lee, S. M. Kim and J. Y. Kim, U.S. Patent, 20090104108, Washington, DC, U.S. Patent and Trademark Office, 2009.

43 K. S. W. Sing, D. H. Everett, R. A. W. Haul, L. Moscou, R. A. Pierotti, J. Rouquerol and T. Siemieniewska, Pure Appl. Chem., 1985, 57, 603. 